In der Rubrik "Literatur kompakt“ werden wichtige Arbeiten aus der internationalen Fachliteratur referiert.

In the Journal Club recent publications from the international literature are evaluated.

\title{
Gräserpille wirkt auch noch nach Jahren
}

Ein internationales Forscherteam hat kürzlich den Langzeiteffekt einer spezifischen Immuntherapie mit einer Gräserpollentablette untersucht - mit positivem Resultat: Die Patienten werden selbst zwei Jahre nach Abschluss der Behandlung signifikant weniger von Rhinokonjunktivitis geplagt

\begin{abstract}
ᄃ in internationales Allergologenteam, - unter ihnen Prof. Dr. Alexander Kapp, Hannover, hatten 634 Freiwillige in ihre randomisierte, placebokontrollierte Studie einbezogen, die an mäßiger bis schwerer Rhinokonjunktivitis aufgrund einer Gräserpollenallergie litten. Medikamentös hatten sie ihre Beschwerden nicht in den Griff bekommen. Geplant war, dass sie drei Jahre lang die Gräserpollenpille Grazax oder Placebo einnehmen, beginnend jeweils vier bis acht Monate vor der Gräserpollensaison, und danach noch zwei Jahre lang nachbeobachtet werden sollten. Primäre Endpunkte waren die Stärke der Rhinokonjunktivitis-Beschwerden sowie der Verbrauch an symptomatisch wirkenden Medikamen-
\end{abstract}

ten. Gesponsert wurde die Untersuchung von ALK-Abelló, Dänemark.

238 Probanden hielten bis zum Ende der Studie durch, 135 in der Verum- und 103 in der Placebogruppe. Der Rhinokonjunktivitis-Symptomscore während der Pollensaison betrug zwei Jahre nach Abschluss der Therapiephase 2,6 für Verum und 3,4 für Placebo. Der schlechteste mögliche Wert war 18. Die Reduktion betrug damit $25 \%$ zugunsten der Pollenpille $(p=0,004)$.

Nach Abschluss der fünf Studienjahre lag der Medikations-Score bei 2,4 für die Gra$\mathrm{zax}^{\oplus}$ - und bei 3,0 für die Placeboprobanden. Dies entsprach zwar einer Reduktion von $20 \%$ unter Verum, allerdings erwies sich diese Abnahme als statistisch nicht signifi-

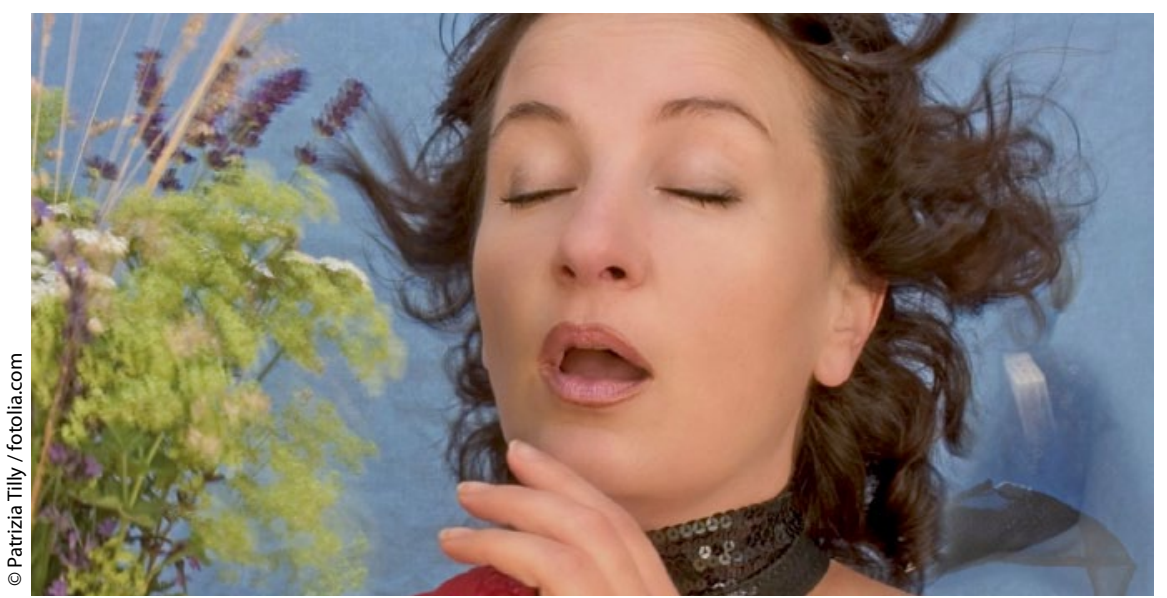

Die Gräserpille macht auch längerfristig Schluss mit der Nieserei zur Pollensaison. kant $(\mathrm{p}=0,114)$. Die Wissenschaftler führen dies zum einen auf eine geringe Pollenbelastung in dieser Saison und auf den Schwund an Studienteilnehmern zurück. In den vier Jahren zuvor hatte der Wert für die benötigte Medikation in der GrazaxGruppe immer signifikant unter jenem in der Placebogruppe gelegen.

Neben diesen Hauptwirkungen - geringere Beschwerden, weniger Medikamente - ließen sich nach der Behandlung mit Gra$\mathrm{zax}^{\oplus}$ weitere positive Effekte beobachten. So senkte die spezifische Immuntherapie (SIT) die Zahl von Tagen, an denen die Patienten während der Hauptexpositionszeit schwer unter ihrer Allergie zu leiden hatten, um gut die Hälfte. Außerdem beeinträchtigte die Rhinokonjunktivitis ihre Lebensqualität nicht mehr so sehr. Stützen konnte diese Befunde die Immunologie. Die Konzentrationen allergenspezifischer $\mathrm{IgG}_{4}$-Antikörper blieben anhaltend hoch, und auch im Serum wirksame Hemmfaktoren, die eine Bindung von AllergenIgE-Komplexen an B-Zellen verhindern, waren nach zwei Jahren noch aktiv.

Fazit: Die SIT mit einer Gräserpollentablette - zusätzlich zu einer symptomatischen medikamentösen Therapie - verändere den Verlauf pollenallergisch bedingter Rhinokonjunktivitis nachhaltig, so das Resümee der Wissenschaftler. Auch zwei Jahre nach der Behandlung wirkte die Therapie mit der Gräserpille immer noch.

Dr. Robert Bublak

Durham SR et al. SQ-standardized sublingual grass immunotherapy: Confirmation of disease modification 2 years after 3 years of treatment in a randomized trial. J Allergy Clin Immunol 2012; 129: 717-25.e5 